\title{
The Economic Impact of New Therapeutic Interventions on Neuropsychiatric Inventory (NPI) Symptom Scores in Patients with Alzheimer Disease
}

\author{
Ali Tafazzoli ${ }^{a} \quad$ Anuraag Kansal $^{a}$ Peter Lockwood ${ }^{b}$ Charles Petrie ${ }^{b}$ \\ Alexandra Barsdorf ${ }^{c}$

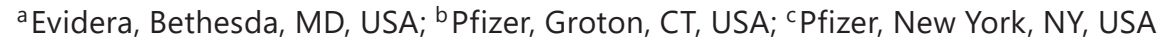

\section{Keywords}

Alzheimer disease · Neuropsychiatric Inventory - Economic analysis · Modeling · Psychiatric medication · Institutionalization · Symptomatic treatment

\begin{abstract}
Background/Aims: Few studies have modeled individual Neuropsychiatric Inventory (NPI) symptom scores for Alzheimer disease (AD) patients and assessed the value of therapeutic interventions that can potentially impact them. The main objective of this study was to evaluate the impact of new AD symptomatic treatments on relevant health economic outcomes via their potential effects on cognition and neuropsychiatric symptoms such as depression, irritability, anxiety, and sleep disorder. Methods: We enhanced the previously published AHEAD model (Assessment of Health Economics in Alzheimer's Disease) by including new variables and functional relations to capture the NPI's individual neuropsychiatric symptoms in addition to the total NPI score. This update allowed us to study the longitudinal effect of improvements in specific NPI subscale scores and the downstream impact on outcomes such as psychiatric medication use, survival, and institutional placement. Results: The model base-case results showed that a hypothetical treatment with symptomatic effects on anxiety, depression, and irritability NPI subscales was not cost-effective; however, the treatment's cost-effectiveness was improved once a direct link between NPI subscales and mortality was explored or under relatively stronger treatment effects. Conclusion: Treatments that influence specific symptoms within the overall NPI have the potential to improve patient outcomes in a cost-effective way. This model is a useful tool for evaluating target product profiles of drugs with effect on NPI symptoms in early stages of development.


Tafazzoli et al.: Economic Impact of New Therapeutic Interventions on NPI Symptom Scores

\section{Introduction}

Alzheimer disease (AD), the most common cause of dementia, is a progressive neurodegenerative brain disease that primarily affects the elderly. The behavioral and psychological symptoms of dementia (BPSD), such as depression, anxiety, and irritability, are a source of significant distress and poor quality of life for patients and their caregivers. BPSD are often measured with the Neuropsychiatric Inventory (NPI) scale, which assesses 12 symptoms based on caregiver information. Individual symptoms within the NPI, however, cover a broad range of behaviors and may differentially predict specific patient outcomes related to psychiatric medication use, institutional placement, and mortality. Few studies have modeled individual NPI symptom scores or assessed the value of therapeutic interventions that can potentially impact them.

The main objective of this study was to evaluate the impact of new symptomatic treatments on relevant health economic outcomes via their potential effects on cognition and neuropsychiatric symptoms such as depression, irritability, anxiety, and sleep disorder. We updated certain components of a previously developed model to accommodate the requirements of the proposed analyses. These updates primarily included (i) employing multivariate sampling to assign individual NPI symptom scores to AD patients based on their total NPI scores, (ii) linking NPI subscales to psychiatric medication use, mortality, and location of care, and (iii) assessing the value of a therapeutic intervention with regards to caregiver burden, psychiatric medication use, or health economic outcomes. This paper shows the results of several hypothetical treatment scenarios and further highlights key assumptions with major impacts on patient outcomes.

\section{Materials and Methods}

\section{Model Overview}

An individual patient simulation was developed in Microsoft Excel ${ }^{\circledR}$, using the discretely integrated condition-event (DICE) approach [1], to estimate the clinical and economic outcomes associated with the introduction of a hypothetical symptomatic treatment in the USA. The model was developed based on the previously published AHEAD model (Assessment of Health Economics in Alzheimer's Disease) [2-5]. The AHEAD model was designed to support the reimbursement of donepezil in the UK [6]. The model simulates disease progression on the basis of cognition (anchored to the Mini-Mental State Examination [MMSE] and Alzheimer's Disease Assessment Scale-Cognitive Subscale [ADAS-Cog]), behavior (based on NPI total score), function (based on activities of daily living [ADL] and instrumental ADL [IADL] scores), and dependence (based on Dependence Scale [DS] scores), and captures interrelated changes in these measures for simulated individuals.

In order to evaluate treatment effect scenarios on psychiatric symptoms, we enhanced the existing model by including new variables and functional relations to capture the NPI's individual neuropsychiatric symptoms in addition to the total NPI score (see Fig. 1). This update allowed us to study the longitudinal effect of improvements in specific NPI subscale scores and the downstream impact on outcomes such as psychiatric medication use, survival, and institutional placement. The symptomatic treatments implemented in the model are hypothetical target product profiles affecting different combinations of NPI symptom scores to improve specific disease symptoms, without altering disease progression.

The AHEAD Model

The AHEAD model uses a set of linear disease progression equations to predict the evolution of AD based on each patient's baseline characteristics (e.g., race, psychiatric medi- 
Tafazzoli et al.: Economic Impact of New Therapeutic Interventions on NPI Symptom Scores

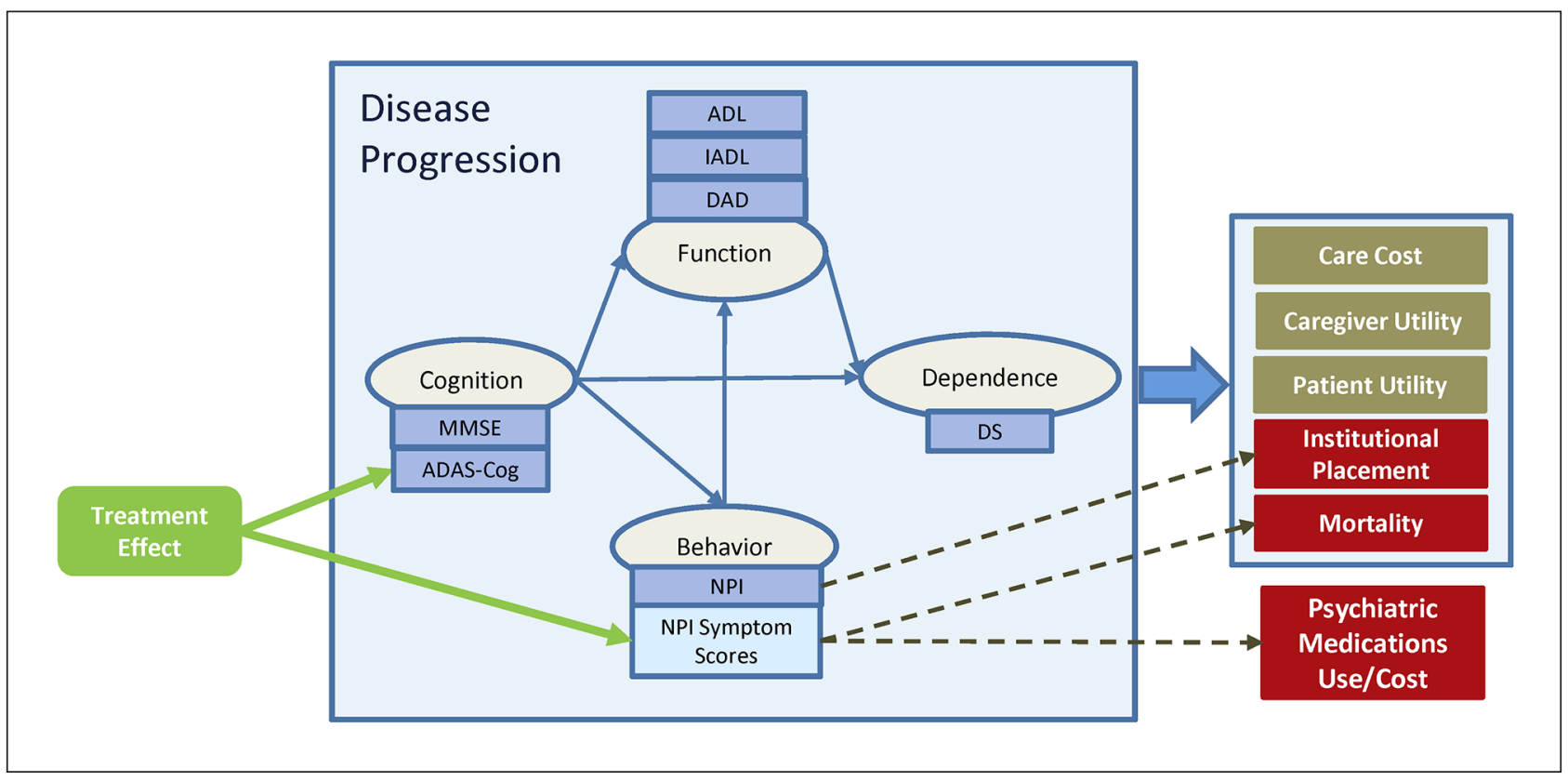

Fig. 1. Key relations in the updated AHEAD model. ADAS-Cog, Alzheimer's Disease Assessment Scale-Cognitive Subscale 13; ADL, activities of daily living; DAD, Disability Assessment scale for Dementia; DS, Dependence Scale; IADL, instrumental activities of daily living; MMSE, Mini-Mental State Examination; NPI, Neuropsychiatric Inventory. Note: dashed lines indicate the links that were explored in scenario analyses.

cation use) and disease history (e.g., rate of cognitive decline). These equations capture the natural history of $\mathrm{AD}$ in terms of change in cognition, function, behavior, and dependence scales, and they use a patient's disease state along with treatment status to predict outcomes such as patient and caregiver quality of life and healthcare resource utilization.

AHEAD equations for MMSE, NPI, ADL, and IADL were derived from individual patient data in the Consortium to Establish a Registry for Alzheimer's Disease (CERAD) data set along with seven donepezil clinical trials; the Disability Assessment scale for Dementia (DAD) and DS equations were derived from the Dependence in Alzheimer's Disease in England (DADE) study [2]. The ADAS-Cog equation was taken from a published equation from Stern et al. [7] (1994).

The equation in the AHEAD model for predicting the total NPI score over time is as follows:

Change from baseline NPI $=5.74+0.03$ weeks $-0.59 \mathrm{NPI}_{\text {baseline }}-0.59 \mathrm{NPI}_{\text {baseline }} \times$ weeks +0.24 NPI $_{\text {recent }}-1.74$ White -3.82 Black +2.34 PsychMed + 0.12 MMSE $_{\text {baseline }}-$ $0.22 \mathrm{MMSE}_{\text {recent }}$

where "weeks" is the time since baseline in weeks, "White" and "Black" are fixed effects for race, and "PsychMed" is a fixed effect for psychiatric medication use.

\section{Model Parameters and Data Sources in the Original AHEAD Model}

The AHEAD model predicts AD disease progression without relying on disease severity levels. However, in the literature, AD severity levels are commonly used as predictors of location of care, mortality, costs of care, and quality of life. Therefore, the AHEAD model first predicts AD disease progression using disease equations and subsequently maps MMSE scores onto stages of disease severity, following the thresholds provided in Perneczky et al. [8] (2006). In the AHEAD model, the results derived from the DADE study are used to assign a probability 
Table 1. NPI symptom score sample characteristics computed from trial data

\begin{tabular}{llll}
\hline NPI symptoms & $\begin{array}{l}\text { Sample } \\
\text { mean }\end{array}$ & $\begin{array}{l}\text { Sample } \\
\text { SD }\end{array}$ & $\begin{array}{l}\text { Sample } \\
\text { skewness }\end{array}$ \\
\hline Delusions & 0.52 & 1.63 & 4.36 \\
Hallucinations & 0.21 & 0.91 & 6.41 \\
Agitation & 0.82 & 1.74 & 2.94 \\
Irritability & 1.05 & 1.99 & 2.51 \\
Depression & 1.08 & 1.91 & 2.38 \\
Anxiety & 1.06 & 2.03 & 2.63 \\
Euphoria & 0.16 & 0.91 & 8.25 \\
Disinhibition & 0.37 & 1.35 & 5.30 \\
Aberrant motor behavior & 1.00 & 2.22 & 2.57 \\
Apathy & 2.09 & 2.87 & 1.27 \\
Sleeping disorder & 0.87 & 2.10 & 2.73 \\
Eating disorder & 1.03 & 2.40 & 2.52 \\
\hline
\end{tabular}

NPI, Neuropsychiatric Inventory; SD, standard deviation.

of institutionalization to each patient based on disease severity level [5]; thus, the risk of institutionalization increases as a patient progresses to the more severe stages of AD. The AHEAD model uses a Weibull parametric equation derived from the analysis of data from the CERAD study to determine the patient's probability of death. This equation predicts survival using the patient's age, sex, and MMSE score at baseline [5] (see Appendix Table A1 for more details).

In the AHEAD model, disease management and care costs are estimated based on a predictive equation extracted from Gustavsson et al. [9] (2011) with parameters on cognition (MMSE), function (DAD), and behavior scales (NPI), as well as coefficients that are selected based on locale of care (community vs. residential) and the patient's current disease severity (defined by the MMSE scale [9]). Care costs are higher for patients in residential care settings than in community dwellings. DAD is the most important predictor of costs of care in the community, whereas for patients in residential care, the only disease severity measure with a significant effect on costs of care is NPI total score. The indirect costs associated with caregiver time and lost productivity are not considered in this model. The AHEAD model uses a predictive equation that estimates patient utility as a function of DS. Caregiver utility is also calculated in the AHEAD model based on a prediction equation from the study of the donepezil trials in terms of patient's sex, psychiatric medication use, MMSE, NPI, ADL, and IADL levels, and caregiver's age and sex (see Appendix for more details).

\section{Model Parameters and Data Sources in the Updated AHEAD Model}

We added inputs in the updated model to derive NPI symptom scores and link them to mortality, psychiatric medication use, and related adverse event (AE) costs. In order to inform these inputs, we performed a targeted literature review of relevant publications and also explored data from patient registries and clinical trials. The literature search indicated that most of the existing publications linking changes in individual NPI symptom scores to health economic outcomes investigated the univariate effect of the item symptom scores; that is, there was a paucity of literature evaluating the effects of individual NPI symptom scores while controlling for the potential influence of the remaining NPI symptom scores [10].

\section{NPI Symptom Scores}

In order to model individual NPI symptom scores, we exploited the correlation structure between the 12 NPI item scores and then used multivariate sampling to compute the indi- 
Tafazzoli et al.: Economic Impact of New Therapeutic Interventions on NPI Symptom Scores

Table 2. Correlation between components of 12 NPI symptom scores for patients from clinical trials (showing just the lower triangle)

\begin{tabular}{|c|c|c|c|c|c|c|c|c|c|c|c|c|}
\hline & Delusions & $\begin{array}{l}\text { Halluci- } \\
\text { nations }\end{array}$ & Agitation & Irritability & Depression & Anxiety & Euphoria & $\begin{array}{l}\text { Disinhi- } \\
\text { bition }\end{array}$ & $\begin{array}{l}\text { Aberrant } \\
\text { motor } \\
\text { behavior }\end{array}$ & Apathy & $\begin{array}{l}\text { Sleeping } \\
\text { disorder }\end{array}$ & $\begin{array}{l}\text { Eating } \\
\text { disorder }\end{array}$ \\
\hline Delusions & 1 & & & & & & & & & & & \\
\hline Hallucinations & 0.38 & 1 & & & & & & & & & & \\
\hline Agitation & 0.29 & 0.13 & 1 & & & & & & & & & \\
\hline Irritability & 0.25 & 0.12 & 0.50 & 1 & & & & & & & & \\
\hline Depression & 0.24 & 0.23 & 0.30 & 0.34 & 1 & & & & & & & \\
\hline Anxiety & 0.23 & 0.16 & 0.26 & 0.31 & 0.40 & 1 & & & & & & \\
\hline Euphoria & 0.05 & 0.01 & 0.16 & 0.20 & 0.09 & 0.07 & 1 & & & & & \\
\hline Disinhibition & 0.10 & 0.11 & 0.20 & 0.29 & 0.16 & 0.18 & 0.31 & 1 & & & & \\
\hline Aberrant motor behavior & 0.20 & 0.06 & 0.28 & 0.33 & 0.23 & 0.26 & 0.22 & 0.21 & 1 & & & \\
\hline Apathy & 0.17 & 0.09 & 0.20 & 0.17 & 0.31 & 0.19 & 0.07 & 0.12 & 0.21 & 1 & & \\
\hline Sleeping disorder & 0.25 & 0.23 & 0.19 & 0.22 & 0.20 & 0.20 & 0.12 & 0.16 & 0.19 & 0.12 & 1 & \\
\hline Eating disorder & 0.03 & 0.09 & 0.13 & 0.17 & 0.20 & 0.13 & 0.12 & 0.19 & 0.16 & 0.19 & 0.15 & 1 \\
\hline
\end{tabular}

vidual symptom scores associated with a total NPI score. We derived the correlation structure by analyzing the baseline NPI symptom scores of 954 AD patients who received a placebo treatment in several AD clinical trials (study details are listed in Appendix Table A2). The overall study sample included patients with mild to moderate AD and a mean MMSE score of 19.10, ADAS-Cog score of 25.32, and total NPI score of 10.26. The sample mean of individual NPI symptom scores along with the pairwise correlation between them were computed using PROC CORR in SAS ${ }^{\circledR}$ version 9.4. The mean scores of NPI symptoms are listed in Table 1, where apathy presented the highest mean symptom score of 2.09 and euphoria showed the lowest score of 0.16 .

The computed pairwise correlations between the 12 symptom scores are also reported in the upper triangle of the matrix shown in Table 2 . The strongest correlations were observed between the agitation-irritability (0.50), anxiety-depression ( 0.40$)$, delusion-hallucination (0.38), and irritability-depression (0.34) subscales, and no negative correlations between subscales were identified. The computed correlation was validated with an external data source, which is discussed later in the paper.

To compute the individual symptom scores associated with total NPI score, the Cholesky decomposition was initially applied to the correlation matrix of the NPI symptom scores, yielding a lower-triangular matrix that permits correlated random numbers to be computed from sequentially drawn independent random numbers. An exponential distribution was then fitted to each individual symptom score considering their highly skewed low means. A large list of NPI symptom score sets was subsequently sampled from the multivariate distributions of the symptom scores and indexed based on the total NPI score of each sampled set.

Using this indexed set, the individual NPI symptom scores can be tracked and updated in the model runs. Before simulating a patient, the patient's baseline total NPI score is randomly matched to an individual NPI score set with the same total NPI score. During the simulation run, the AHEAD NPI equation (Eq. 1) is used to simulate total NPI score over time, and changes in total NPI score are proportionally added to each NPI symptom score. Individual NPI scores are limited to a range (0-12), so where proportional changes would exceed the score limits for a symptom, the excess is redistributed across other symptoms equally. Treatment effects are applied directly to each symptom score and summed up to compute the total NPI score with treatment.

The NPI symptom scores and other disease markers (e.g., ADAS, MMSE) are then used in the model over time to predict $\mathrm{AD}$ progression and assess treatment effects on caregiver 
Table 3. Probability of initiating psychiatric medication use based on NPI symptom score levels

\begin{tabular}{l|l}
\hline Dement Geriatr Cogn Disord Extra 2018;8:158-173 \\
\hline DOI: 10.1159/000488140 & $\begin{array}{l}\text { @ 2018 The Author(s). Published by S. Karger AG, Basel } \\
\text { www.karger.com/dee }\end{array}$ \\
\hline
\end{tabular}

Tafazzoli et al.: Economic Impact of New Therapeutic Interventions on NPI Symptom Scores

\begin{tabular}{lll}
\hline Psychiatric medication & \multicolumn{2}{l}{ Patients on medication, \% } \\
\cline { 2 - 3 } & $\begin{array}{l}\text { symptom } \\
\text { score }<4\end{array}$ & $\begin{array}{l}\text { symptom } \\
\text { score } \geq 4\end{array}$ \\
\hline Antipsychotics & & \\
$\quad$ Linked to psychosis & 0.21 & 0.4 \\
$\quad$ Linked to anxiety & 0.22 & 0.37 \\
$\quad$ Linked to agitation & 0.23 & 0.33 \\
Antidepressants & 0.34 & 0.6 \\
$\quad$ Linked to depression & 0.37 & 0.48 \\
$\quad$ Linked to anxiety & 0.21 & 0.34 \\
Anxiolytics & 0.2 & 0.38 \\
$\quad$ Linked to depression & Linked to anxiety & \\
\hline
\end{tabular}

Source: Selbaek et al. [11] (2007).

Table 4. Base-case scenario setting

\begin{tabular}{ll}
\hline Inputs & Setting \\
\hline Time horizon & 10 years \\
Patient disease severity & AD patients (mild, moderate, and severe) in community dwelling \\
Annual treatment cost & USD 4,383 (medication only) \\
Treatment discontinuation & No treatment discontinuation/waning \\
Treatment effect & 1-point change in anxiety, depression, and irritability NPI subscales \\
& 1.5-point change in ADAS-Cog \\
& No effect on risk of institutional placement \\
Psychiatric medication & NPI psychosis symptom linked to antipsychotics use \\
& NPI depression symptom linked to antidepressant use \\
& NPI anxiety symptom linked to anxiolytics \\
& No AE cost associated with psychiatric medication use \\
\hline
\end{tabular}

ADAS-Cog, Alzheimer's Disease Assessment Scale-Cognitive Subscale 13; AD, Alzheimer disease; AE, adverse event; NPI, Neuropsychiatric Inventory.

burden, psychiatric medication use, and health economic outcomes. In this model, the change in individual NPI symptom scores can be mapped directly to risk of mortality and psychiatric medication use, but they do not differentially map to the measures of cognition and function.

Mortality

The longitudinal change in NPI symptom scores may also be used in the updated model to adjust the risk of mortality. The study results by Spalletta et al. [10] (2015) provided specific hazard ratios of the risk of mortality for every unit increase in selected NPI symptom scores where significant effects were reported in a Cox survival model. The following mortality hazard ratios from Spalletta et al. (2015) are included in the model and can be selected one at a time to adjust the risk of mortality: anxiety (1.18), depression (1.09), irritability (1.08), sleep disorder (1.48), apathy (1.24), and aberrant motor behavior (1.25).

Psychiatric Medication Use

The updated model uses the results from a study by Selbaek et al. [11] (2007) to link changes in certain NPI symptom scores to psychiatric medicine use such as antipsychotics, 
Table 5. Treatment scenarios

\begin{tabular}{|c|c|c|}
\hline No. & Scenario & Purpose \\
\hline 1 & Varying treatment cost & $\begin{array}{l}\text { To determine a treatment cost that is economically justified under base-case } \\
\text { assumptions }\end{array}$ \\
\hline 2 & $\begin{array}{l}\text { Treatment effect on psychiatric } \\
\text { medication use }\end{array}$ & $\begin{array}{l}\text { To determine whether changing NPI symptoms that are linked to psychiatric } \\
\text { medication use can play any role in better capturing treatment effects }\end{array}$ \\
\hline 3 & Including cost of AEs & $\begin{array}{l}\text { To explore how much the new treatment can impact the AE costs associated } \\
\text { with psychiatric medication use }\end{array}$ \\
\hline 4 & Varying time horizon & $\begin{array}{l}\text { To compare the cost-effectiveness of the new treatment in the short term vs. } \\
\text { long term }(2,5,10,20 \text { years })\end{array}$ \\
\hline 5 & Treatment discontinuation $^{\mathrm{a}}$ & $\begin{array}{l}\text { To determine how cost-effective the new treatment would be if it was } \\
\text { discontinued after } 1,2 \text {, or } 5 \text { years }\end{array}$ \\
\hline 6 & Varying disease severity & $\begin{array}{l}\text { To determine how patients with different AD disease severity benefit from } \\
\text { the new treatment }\end{array}$ \\
\hline 7 & $\begin{array}{l}\text { Redistributing treatment effects } \\
\text { among NPI subscales }\end{array}$ & $\begin{array}{l}\text { To determine the treatment effects on which combination of NPI subscales } \\
\text { results in a greater benefit }\end{array}$ \\
\hline 8 & $\begin{array}{l}\text { Increasing treatment effects on } \\
\text { NPI subscales and ADAS-Cog }\end{array}$ & $\begin{array}{l}\text { To determine the total treatment effects required to make the new treatment } \\
\text { cost-effective }\end{array}$ \\
\hline 9 & $\begin{array}{l}\text { Changing longitudinal effect of } \\
\text { NPI subscales on mortality }\end{array}$ & $\begin{array}{l}\text { To explore the effect of directly linking the change in NPI symptom scores to } \\
\text { mortality hazard }\end{array}$ \\
\hline 10 & $\begin{array}{l}\text { Linking NPI subscales to risk of } \\
\text { institutional placement }\end{array}$ & $\begin{array}{l}\text { To explore the effect of new treatment in reducing the risk of } \\
\text { institutionalization }\end{array}$ \\
\hline 11 & $\begin{array}{l}\text { Combined effects of scenarios } \\
3,4,6,8 \text {, and } 9\end{array}$ & To explore the maximum effect achievable \\
\hline
\end{tabular}

ADAS-Cog, Alzheimer's Disease Assessment Scale-Cognitive Subscale 13; AD, Alzheimer disease; AE, adverse event; NPI, Neuropsychiatric Inventory. ${ }^{\text {a }}$ Treatment discontinuation resulted in a return to clinical values as if the patient had never been treated.

antidepressants, and anxiolytics. In Selbaek et al. (2007), patients who exhibited a score of $\geq 4$ on a single NPI symptom score were categorized as patients with clinically significant symptoms who have a higher risk of being on psychiatric medication. Table 3 illustrates the inputs from the study by Selbaek et al. [11] (2007) used in the updated model to determine the percentage of patients on psychiatric medication according to NPI symptom score levels. Thus, if a simulated subject's NPI symptom scores for hallucinations and delusions (collectively noted as psychosis) were $<4$, there would be a $21 \%$ chance that the patient would be assigned an antipsychotic.

The updated model includes an option to add mean annual AE costs for fractures and falls associated with the use of psychiatric medication to evaluate the health economic consequences of being on psychiatric medication.

\section{Base-Case Analysis}

In the base-case analysis, we simulated $1,000 \mathrm{AD}$ patients with mild, moderate, or severe disease and an average MMSE of 19 for a 10-year time horizon. A hypothetic symptomatic treatment was defined and compared to a placebo arm with symptomatic effects defined in Table 4 . The treatment effect plateaued by 6 months, and then the effect was maintained till 
Tafazzoli et al.: Economic Impact of New Therapeutic Interventions on NPI Symptom Scores

Table 6. Correlation between components of 10 NPI symptom scores for patients from the study of Garre-Olmo et al. (showing just the lower triangle)

\begin{tabular}{|c|c|c|c|c|c|c|c|c|c|c|}
\hline & Delusions & Hallucinations & Agitation & Irritability & Depression & Anxiety & Euphoria & $\begin{array}{l}\text { Disinhi- } \\
\text { bition }\end{array}$ & $\begin{array}{l}\text { Aberrant } \\
\text { motor } \\
\text { behavior }\end{array}$ & Apathy \\
\hline Delusions & 1 & & & & & & & & & \\
\hline Hallucinations & 0.47 & 1 & & & & & & & & \\
\hline Agitation & 0.33 & 0.25 & 1 & & & & & & & \\
\hline Irritability & 0.31 & 0.24 & 0.52 & 1 & & & & & & \\
\hline Depression & 0.18 & 0.14 & 0.30 & 0.28 & 1 & & & & & \\
\hline Anxiety & 0.11 & 0.09 & 0.18 & 0.17 & 0.31 & 1 & & & & \\
\hline Euphoria & 0.09 & 0.07 & 0.08 & 0.08 & 0.05 & 0.03 & 1 & & & \\
\hline Disinhibition & 0.19 & 0.14 & 0.19 & 0.18 & 0.10 & 0.06 & 0.23 & 1 & & \\
\hline Aberrant motor behavior & 0.23 & 0.18 & 0.23 & 0.22 & 0.12 & 0.08 & 0.10 & 0.21 & 1 & \\
\hline Apathy & 0.21 & 0.16 & 0.21 & 0.20 & 0.20 & 0.07 & 0.09 & 0.19 & 0.24 & 1 \\
\hline
\end{tabular}

Table 7. Results for base-case scenario

\begin{tabular}{llll}
\hline & Placebo & Treatment & $\begin{array}{l}\text { Difference } \\
\text { (treatment vs. placebo) }\end{array}$ \\
\hline ICER, USD & & & 344,425 \\
\hline Cost outcomes, USD & & & \\
Total cost & 181,123 & 196,519 & 15,396 \\
Care cost & 181,123 & 171,815 & $(9,308)$ \\
Drug cost & 0 & 24,703 & 24,703 \\
\hline Health outcomes & & & \\
Patient QALYs & 3.73 & 3.77 & 0.045 \\
Patient life-years & 5.64 & 5.64 & 0 \\
Caregiver QALYs & 3.60 & 3.61 & 0.01 \\
\hline $\begin{array}{l}\text { Psychiatric medication } \text { use, years } \\
\text { Time on psychiatric medication }\end{array}$ & & & \\
Time on antipsychotics & 4.42 & 4.18 & $(0.24)$ \\
Time on antidepressants & 1.18 & 1.18 & $(0.002)$ \\
Time on anxiolytics & 2.63 & 2.44 & $(0.19)$ \\
\hline Residential care, \% & 1.78 & 1.72 & $(0.05)$ \\
Time in residential care, years & 30 & 28 & $(2)$ \\
Mortality, \% & 1.57 & 1.52 & $(0.05)$ \\
\hline
\end{tabular}

ICER, incremental cost-effectiveness ratio; QALY, quality-adjusted life-year.

the end of the 10-year time horizon. In the base case, no treatment effect was assumed on the risk of institutional placement and the risk of mortality was not adjusted based on the change in NPI symptom scores. The annual cost of the hypothetical treatment was set in parity with memantine at USD 4,383/year and considered to be cost-effective at USD 150,000/qualityadjusted life-year (QALY).

\section{Scenario Analysis}

The list of scenarios and their purpose in this simulation study are provided in Table 5. These scenarios were explored to recognize the impact of key inputs on model outcomes. 
Validation of NPI Symptom Score Calculations

To assess the generalizability of the derived correlation matrix, we compared this matrix to a correlation matrix computed from the results of an independent exploratory and confirmatory factor analysis conducted by Garre-Olmo et al. [12] (2010) in which they grouped the BPSD for a sample population of 491 mild to moderate AD patients. In the confirmatory factor analysis, 10 NPI subscales (except sleep and eating disorder) were grouped in three categories of psychotic, emotional, and behavior clinical syndromes, and the correlation structure between symptom groups and subscales was derived based on the factorial grouping of the NPI subscales. We used the correlation data reported in this paper and computed the pairwise correlations between all NPI symptom scores (see Table 6).

\section{Results}

\section{Base-Case Results}

The base-case results showed that the hypothetical symptomatic treatment was not costeffective compared to the placebo (Table 7). The total costs, including care and drug acquisition costs, were estimated to be USD 196,519 with the new treatment, compared with USD 181,123 for placebo over a 10-year time horizon. The decrease in total care cost (-USD 9,308) was offset by the increase in the drug acquisition cost (USD 24,703), leading to a total cost increase of USD 15,396 over 10 years. QALYs were increased with the new treatment, with an incremental improvement of 0.045 . The total percentage of patients institutionalized decreased by $2 \%$, and the average time in institutional care and on psychiatric medication use decreased by 0.051 years ( $\sim 19$ days) and 0.24 years ( 3 months), respectively, for the new treatment compared with placebo. The incremental cost-effectiveness ratio (ICER) was USD 344,425/QALY which is well above a currently acceptable threshold of USD 150,000/QALY.

\section{Scenario Analyses Results}

A $5 \%$ reduction in drug cost (scenario 1) had a modest impact on the ICER, reducing it by $\sim$ USD 28,000/QALY to USD 316,793/QALY. The hypothetical treatment was cost-effective when the annual drug price was reduced by $35 \%$ to USD 2,836 .

In the second scenario, we altered the NPI symptoms that were linked to antipsychotic, antidepressant, and anxiolytic use and studied the mean difference in the time patients spent on various psychiatric medications in the treatment and placebo arms. Under the alternative settings, the reduction in average time on psychiatric medication did not improve $(-0.19$, -0.09 years), and the base-case setting was superior overall. Hence, changing NPI symptoms that are linked to psychiatric medication use played a small role in better capturing the proposed treatment effects in this analysis.

The ICER decreased by only USD 3000, 14,000, and 28,000/QALY when annual AE costs of USD 1000, 5000, and 10,000, respectively, were considered for fractures and falls due to psychiatric medication use (scenario 3). Based on these outcomes, it was unlikely that the new treatment could provide enough AE cost savings to be cost-effective.

In scenario 4, we compared the ICER under different time horizons. With a 2-year time horizon, the ICER increased to USD 524,234/QALY; however, after 5 years, no significant change was observed in ICERs compared to the base-case scenario (USD 373,091/QALY and 334,453/QALY for the 5- and 20-year time horizons, respectively). The new treatment value was largely realized within 5 years of treatment.

The results of scenario 5 indicated that the new treatment's economic value was lower if it was discontinued within 2 years (USD 511,093 and 442,807/QALY for discontinuation after 1 and 2 years, respectively), similar to the scenario using a 2 -year time horizon. In contrast, 
Tafazzoli et al.: Economic Impact of New Therapeutic Interventions on NPI Symptom Scores

Table 8. Results for redistributing treatment effects on NPI subscales

\begin{tabular}{|c|c|c|c|c|c|}
\hline & Base case & $\begin{array}{l}3 \text { points on } \\
\text { depression }\end{array}$ & $\begin{array}{l}3 \text { points on } \\
\text { anxiety }\end{array}$ & $\begin{array}{l}3 \text { points on } \\
\text { irritability }\end{array}$ & $\begin{array}{l}3 \text { points on sleep } \\
\text { disorder }\end{array}$ \\
\hline ICER, USD & 344,425 & 384,656 & 401,152 & 398,010 & 501,946 \\
\hline $\begin{array}{l}\text { Cost outcomes, USD } \\
\text { Care cost }\end{array}$ & $(9,308)$ & $(8,202)$ & $(7,815)$ & $(7,868)$ & $(3,923)$ \\
\hline $\begin{array}{l}\text { Health outcomes } \\
\text { Patient QALYs } \\
\text { Caregiver QALYs }\end{array}$ & $\begin{array}{l}0.045 \\
0.01\end{array}$ & $\begin{array}{l}0.043 \\
0.008\end{array}$ & $\begin{array}{l}0.042 \\
0.007\end{array}$ & $\begin{array}{l}0.042 \\
0.009\end{array}$ & $\begin{array}{l}0.041 \\
0\end{array}$ \\
\hline $\begin{array}{l}\text { Psychiatric medication use } \\
\text { Time on psychiatric medication } \\
\text { Time on antipsychotics } \\
\text { Time on antidepressants } \\
\text { Time on anxiolytics }\end{array}$ & $\begin{array}{l}(0.24) \\
(0.002) \\
(0.19) \\
(0.05)\end{array}$ & $\begin{array}{l}(0.25) \\
(0.002) \\
(0.25) \\
(0.002)\end{array}$ & $\begin{array}{l}(0.21) \\
(0.002) \\
(0.002) \\
(0.26)\end{array}$ & $\begin{array}{l}(0.005) \\
(0.002) \\
(0.002) \\
(0.002)\end{array}$ & $\begin{array}{l}(0.005) \\
(0.002) \\
(0.002) \\
(0.002)\end{array}$ \\
\hline & $\begin{array}{l}1 \text { point on } \\
\text { depression, } \\
\text { irritability and } \\
\text { sleep disorder }\end{array}$ & $\begin{array}{l}2 \text { points on } \\
\text { anxiety, } 1 \text { point } \\
\text { on depression }\end{array}$ & $\begin{array}{l}2 \text { points on } \\
\text { depression, } \\
1 \text { point on } \\
\text { anxiety }\end{array}$ & $\begin{array}{l}2 \text { points on } \\
\text { sleep disorder, } \\
1 \text { point on } \\
\text { irritability }\end{array}$ & $\begin{array}{l}2 \text { points on } \\
\text { irritability, } \\
1 \text { point on sleep } \\
\text { disorder }\end{array}$ \\
\hline ICER, USD & 382,565 & 361,340 & 357,380 & 438,349 & 404,607 \\
\hline $\begin{array}{l}\text { Cost outcomes, USD } \\
\text { Care cost }\end{array}$ & $(7,603)$ & $(8,841)$ & $(8,943)$ & $(5,723)$ & $(7,022)$ \\
\hline $\begin{array}{l}\text { Health outcomes } \\
\text { Patient QALYs } \\
\text { Caregiver QALYs }\end{array}$ & $\begin{array}{l}0.045 \\
0.007\end{array}$ & $\begin{array}{l}0.04 \\
0.008\end{array}$ & $\begin{array}{l}0.04 \\
0.01\end{array}$ & $\begin{array}{l}0.04 \\
0.004\end{array}$ & $\begin{array}{l}0.04 \\
0.007\end{array}$ \\
\hline $\begin{array}{l}\text { Psychiatric medication use, years } \\
\text { Time on psychiatric medication } \\
\text { Time on antipsychotics } \\
\text { Time on antidepressants } \\
\text { Time on anxiolytics }\end{array}$ & $\begin{array}{l}(0.19) \\
(0.002) \\
(0.19) \\
(0.002)\end{array}$ & $\begin{array}{l}(0.39) \\
(0.002) \\
(0.19) \\
(0.26)\end{array}$ & $\begin{array}{l}(0.28) \\
(0.002) \\
(0.23) \\
(0.05)\end{array}$ & $\begin{array}{l}(0.005) \\
(0.002) \\
(0.002) \\
(0.002)\end{array}$ & $\begin{array}{l}(0.005) \\
(0.002) \\
(0.002) \\
(0.002)\end{array}$ \\
\hline
\end{tabular}

The reported results are differences between treatment and placebo arms. ICER, incremental cost-effectiveness ratio; QALY, qualityadjusted life-year.

Table 9. Results of applying different treatment effects on depression, irritability, and anxiety NPI subscales

\begin{tabular}{llllll}
\hline & Base case & $\begin{array}{l}\text { 1.33-point } \\
\text { reduction in } \\
\text { 3 subscales }\end{array}$ & $\begin{array}{l}\text { 2-point } \\
\text { reduction in } \\
\text { 3 subscales }\end{array}$ & $\begin{array}{l}\text { 3-point } \\
\text { reduction in } \\
\text { 3 subscales }\end{array}$ & $\begin{array}{l}\text { 3-point } \\
\text { reduction in } \\
\text { ADAS-Cog }\end{array}$ \\
\hline ICER, USD & 344,425 & 295,288 & 221,067 & 148,582 & 141,619 \\
\hline $\begin{array}{l}\text { Cost outcomes, USD } \\
\text { Care cost }\end{array}$ & $(9,308)$ & $(10,854)$ & $(13,562)$ & $(16,650)$ & $(13,190)$ \\
\hline $\begin{array}{l}\text { Health outcomes } \\
\begin{array}{l}\text { Patient QALYs } \\
\text { Caregiver QALYs }\end{array}\end{array}$ & 0.045 & 0.047 & 0.050 & 0.054 & 0.081 \\
\hline
\end{tabular}

The reported results are differences between the treatment and placebo arms. ADAS-Cog, Alzheimer's Disease Assessment Scale-Cognitive Subscale 13; ICER, incremental cost-effectiveness ratio; QALY, qualityadjusted life-year. 
Tafazzoli et al.: Economic Impact of New Therapeutic Interventions on NPI Symptom Scores

Table 10. Results of linking mortality with change in different NPI subscale scenarios

\begin{tabular}{|c|c|c|c|c|c|c|}
\hline & Base case & $\begin{array}{l}\text { Mortality } \\
\text { linked to } \\
\text { anxiety }\end{array}$ & $\begin{array}{l}\text { Mortality } \\
\text { linked to } \\
\text { depression }\end{array}$ & $\begin{array}{l}\text { Mortality } \\
\text { linked to } \\
\text { apathy }\end{array}$ & $\begin{array}{l}\text { Mortality } \\
\text { linked to } \\
\text { irritability }\end{array}$ & $\begin{array}{l}\text { Mortality } \\
\text { linked to sleep } \\
\text { disorder }\end{array}$ \\
\hline ICER, USD & 344,425 & 152,535 & 183,321 & 307,548 & 201,605 & 299,865 \\
\hline \multicolumn{7}{|l|}{ Cost outcomes, USD } \\
\hline Total cost & 15,396 & 24,192 & 20,697 & 14,516 & 19,818 & 14,453 \\
\hline Care cost & $(9,308)$ & 57 & $(3,451)$ & $(7,442)$ & $(4,534)$ & $(7,491)$ \\
\hline Drug cost & 24,703 & 24,135 & 24,148 & 21,958 & 24,352 & 21,945 \\
\hline \multicolumn{7}{|l|}{ Health outcomes } \\
\hline Patient QALYs & 0.045 & 0.159 & 0.113 & 0.047 & 0.098 & 0.048 \\
\hline Caregiver QALYs & 0.01 & 0.13 & 0.09 & 0.02 & 0.07 & 0.02 \\
\hline \multicolumn{7}{|l|}{ Psychiatric medication use, years } \\
\hline Time on psychiatric medication & $(0.24)$ & $(0.04)$ & $(0.13)$ & $(0.2)$ & $(0.15)$ & $(0.19)$ \\
\hline
\end{tabular}

The reported results are differences between treatment and placebo arms. ICER, incremental cost-effectiveness ratio; QALY, quality-adjusted life-year.

the ICER for treatment discontinuation after 5 years was very close to that seen with the no-discontinuation scenario in the base case (USD 350,063/QALY vs. 344,425/QALY). This suggests that there is little additional benefit for treatment beyond 5 years, consistent with the assumption of symptomatic effect only.

In scenario 6, the new treatment demonstrated a better economic value once it was studied in more severe AD patients (MMSE 10-15, USD 319,025/QALY) vs. patients early in their disease course (MMSE 25-30, USD 400,679/QALY; MMSE 20-25, USD 362,043/QALY; MMSE 15-20, USD 339,738/QALY).

Scenario 7 examined the impact of redistributing the 3-point change in total NPI treatment effect considered in the base-case scenario across four different NPI subscales (anxiety, depression, irritability, and sleep disorder) in order to determine the combination of subscales that may best reveal a treatment effect. The results indicated that the base-case distribution of treatment effects ( 1 point on depression, irritability, anxiety) provided the lowest ICER compared to other alternatives (see Table 8). The largest treatment effect on psychiatric medication use was observed when treatment effect was redistributed between the anxiety and depression subscales.

Subsequently, in scenario 8, we explored the impact of uniformly increasing the total treatment effects on the depression, irritability, and anxiety subscales and the ADAS-Cog cognition scale (see Table 9). The results indicated that to make the new treatment costeffective, a 2-point change would be needed in each of the three NPI subscales (i.e., 9-point change in total NPI) or 1.5 additional points in ADAS-cog.

In scenario 9, we explored the effect of the new treatment on mortality via a temporal improvement in the NPI subscales (Table 10). Linking the anxiety subscale to mortality had the largest effect on the economic value of the new treatment; the depression and irritability subscales were the next two subscales with the largest effects. Reducing mortality also overwhelmed the modest direct NPI effect on psychiatric medication use. More robust data on the relation between individual symptoms and mortality will help assess the value of new treatments.

Applying a treatment-specific hazard of 0.94 to the risk of institutional care (scenario 10) resulted in a $2 \%$ reduction in the percentage of patients institutionalized and a reduction of 
Table 11. Results of multi-way sensitivity analysis scenarios

\begin{tabular}{llll}
\hline & Base case & $\begin{array}{l}\text { Multi-way } \\
\text { scenario 1 }\end{array}$ & $\begin{array}{l}\text { Multi-way } \\
\text { scenario 2 }\end{array}$ \\
\hline ICER, USD & 344,425 & 149,156 & 126,103 \\
\hline $\begin{array}{l}\text { Cost outcomes, USD } \\
\text { Total cost }\end{array}$ & 15,396 & 31,979 & 33,543 \\
Care cost & $(9,308)$ & 5,488 & 6,758 \\
Drug cost & 24,703 & 26,492 & 26,786 \\
Psychiatric medication use AE cost & 0 & 825 & 958 \\
\hline Health outcomes & & & \\
Patient QALYs & 0.045 & 0.214 & 0.266 \\
Caregiver QALYs & 0.01 & 0.2 & 0.24 \\
\hline Psychiatric medication use, years & & & \\
Time on psychiatric medication & $(0.24)$ & 0.24 & 0.28 \\
Time on antipsychotics & $(0.002)$ & 0.11 & 0.13 \\
Time on antidepressants & $(0.19)$ & 0.12 & 0.13 \\
Time on anxiolytics & $(0.05)$ & 0.1 & 0.13 \\
\hline Residential care, \% & -2 & 0 & -1 \\
Time in residential care, years & $(0.05)$ & 0.15 & 0.2 \\
Mortality, \% & 0 & 0 & 0 \\
\hline
\end{tabular}

The reported results are differences between treatment and placebo arms. AE, adverse event; ICER, incremental cost-effectiveness ratio; QALY, quality-adjusted life-year.

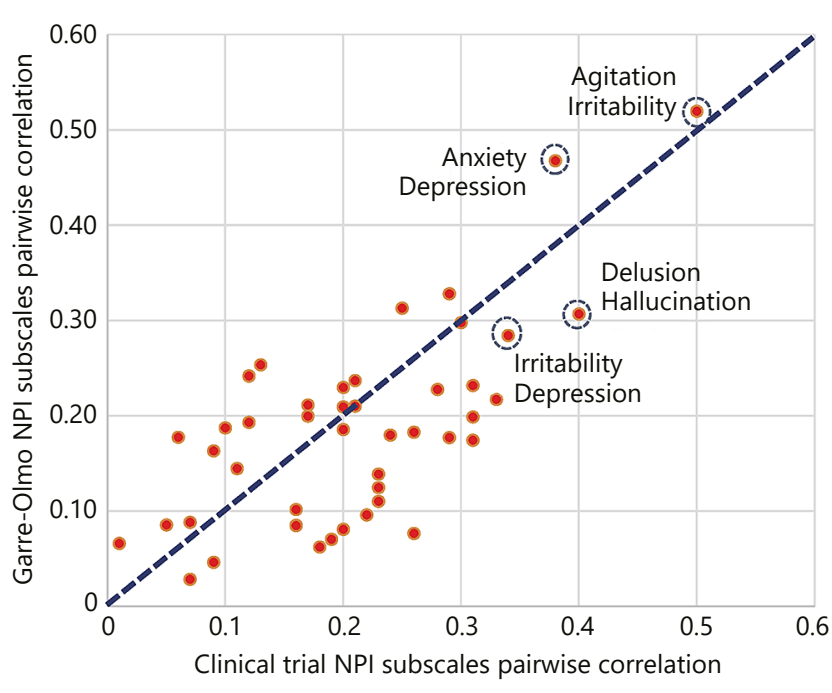

Fig. 2. Comparison of NPI subscales pairwise correlations computed based on the clinical trial data and data from the study of Garre-Olmo et al. [12] (2010) .

USD 2,367 in the care cost of AD patients. Caregiver QALYs diminished slightly under this scenario since the caregivers had to provide care for a longer time before patients were institutionalized. The resulting ICER was USD 291,482/QALY.

Scenario 11 explored multi-way scenarios that combined favorable one-way scenarios to find a cost-effective treatment (Table 11). The first multi-way analyses examined AD patients 
with MMSE $\leq 20$ for a 20-year time horizon, linked mortality to anxiety, and considered an AE annual cost of USD 5,000 associated with psychiatric medication use. The resulting ICER for this scenario was USD 149,156/QALY; a marginal improvement was seen compared to scenario 9, where only mortality and anxiety were linked (USD 152,535/QALY). The second multi-way analyses changed the base-case total treatment effects in addition to the changes in the first multi-way analyses. It considered 1.33-point reductions in the anxiety, depression, and irritability NPI subscales and a 2-point reduction in ADAS-Cog. This scenario resulted in a lower ICER of USD 126,103/QALY.

\section{Validation Results on NPI Symptom Score Calculations}

The magnitude of pairwise correlations computed from the patient-level clinical trial data and the study of Garre-Olmo et al. [12] was mostly consistent. The results presented in Figure 2 show that the pairwise correlations for NPI symptom score computed from the patient-level clinical trial data are spread narrowly around the line of unity when compared against the correlations computed from Garre-Olmo et al. (2010). These observations support the generalizability of the proposed correlation structure in the model. The correlations obtained from the trial data analysis also showed evidence of psychotic (strong correlation between delusion and hallucination [0.38]) and emotional factors (strong correlations between agitation, irritability, depression, and anxiety [range: $0.26-0.50]$ ]) as indicated by the study of Garre-Olmo et al. [12] (2010). However, limited indication was found for a behavioral factor in the trial data analysis.

\section{Discussion}

The updated AHEAD model may be useful to examine the potential effect of new drugs on NPI symptom scores and specifically their link to psychiatric medication use and background mortality. This model can further be used to study which neuropsychological or behavioral symptom clusters may be most associated with treatment impact on institutionalization and caregiver burden. In this context, the model is a useful tool for evaluating target product profiles of a drug in early stages of development that may potentially affect NPI symptoms.

The results of the scenario analyses also showed that while the hypothetical treatment was not cost-effective in the base case, its cost-effectiveness was improved in several scenarios. We demonstrated substantial improvements when considering the direct link between NPI subscales and mortality, and when exploring relatively stronger treatment effects compared to the base-case scenario. More modest benefits were also observed once we increased the costs associated with psychiatric medication use or looked at more severe patient populations. The other interesting observation was that improvements in mortality resulted in a greater beneficial impact on the cost-effectiveness of treatment than the NPI effect on psychiatric medication use, the associated costs of which may diminish the cost-effectiveness of the new treatment.

The correlation study of individual NPI symptom scores together with the corresponding validation task showed that the correlation structure between these symptoms was robust across unrelated data sets and thus can be exploited for modeling NPI symptoms. The advantage of this approach is that it can be easily translated to accommodate new trial data for other studies.

While application of the model can assist in decision making, there are some limitations to its current form. One limitation is that there is no integration of uncertainty in the treatment effect. The treatment effect input is the same for each iteration of a simulation and the implication is that we do not have a reliable estimate of the upper or lower bounds of the range of 
Tafazzoli et al.: Economic Impact of New Therapeutic Interventions on NPI Symptom Scores

the treatment effects. Another limitation is that the model does not take into account the differential impact that individual domain scores may have on function at different stages of AD. Individual NPI scores sum to a total NPI score, which then feeds into estimates of function and utility. Thus, a 3-point change in one item would have the same impact on function as a 1-point change in three items in the same individual. Future versions of the model will consider the inclusion of the treatment effect variability and the differential impact of various patterns of item scores on function.

\section{Conclusion}

This preliminary version of an enhanced AHEAD model may be useful to examine the effect of new drugs on NPI symptom scores and associated target product profiles for drug development. Treatments that influence specific symptoms within the overall NPI have the potential to improve patient outcomes in a cost-effective way, contingent, of course, on the effect size and treatment costs in specific patient populations. In the current modeling study, the largest benefit was driven by changes in patient mortality and in individual NPI symptoms associated with mortality. More robust direct observations on the relation between individual NPI symptoms and patient outcomes will help to inform the potential value of such treatments.

\section{Statement of Ethics}

The studies were conducted in accordance with the Declaration of Helsinki, local independent ethics committee/institutional review board requirements, and good clinical practice guidelines. Informed consent was obtained from all individual participants included in the study.

\section{Disclosure Statement}

Charles Petrie, Alexandra Barsdorf, and Peter Lockwood are employed by Pfizer (and may own Pfizer stock or stock options). Anuraag Kansal and Ali Tafazzoli are employed by Evidera, which provides consulting and other research services to pharmaceutical, medical device, and related organizations. In their salaried positions, they work with a variety of companies and organizations, and are precluded from receiving payment or honoraria directly from these organizations for services rendered. Evidera received funding from Pfizer to participate in the study and the development of this paper.

\section{Funding Sources}

Pfizer provided the funding for the study and for the development of the paper.

\section{Author Contributions}

All authors participated in data analysis and interpretation, and contributed to the development of the manuscript. All named authors meet the International Committee of Medical Journal Editors (ICMJE) criteria for authorship for this paper, take responsibility for the integrity of the work as a whole, and have given final approval to the version to be published. 
Tafazzoli et al.: Economic Impact of New Therapeutic Interventions on NPI Symptom Scores

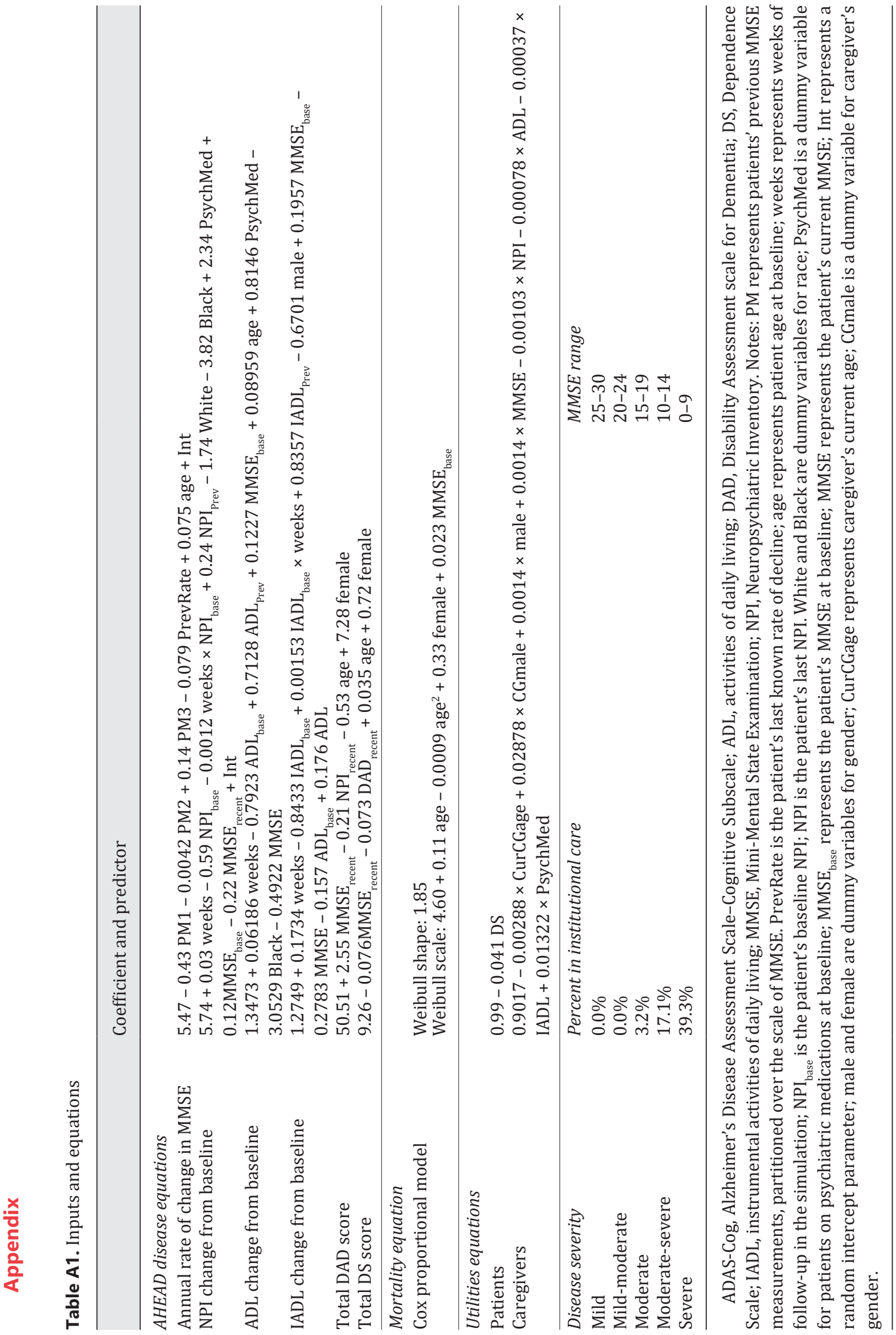


Table A2. Data sources for modeling

\begin{tabular}{|c|c|c|}
\hline Trial description & $\begin{array}{l}\text { Placebo } \\
\text { subjects, } n\end{array}$ & Study details \\
\hline $12 \mathrm{~W}, \mathrm{DB}, \mathrm{PC}$ study & 75 & $\begin{array}{l}\text { Patients stratified on baseline MMSE of } 26 \text { through } 21 \text { or } 20 \text { through } \\
\text { 12; Visits @ BL, 6W, 12W; No use of Mem or ChI within 3M of the } \\
\text { baseline visit }\end{array}$ \\
\hline $\begin{array}{l}6 \mathrm{M}, \mathrm{DB}, \mathrm{PC} \text {, study } \\
\text { outpatients with AD } \\
\text { treated with ChI }\end{array}$ & 85 & $\begin{array}{l}\text { MMSE score of } 12 \text { to } 26 \text {; ChI use required and must have been } \\
\text { administered for } 3 \mathrm{M} \text { before the BL visit; Visits at BL, } 6 \mathrm{~W}, 12 \mathrm{~W}, 24 \mathrm{~W}\end{array}$ \\
\hline 18M, PC study & 58 & $\begin{array}{l}\text { Visits @ BL, 3M, 5M, 7M, 13M, follow-up at } 19 \mathrm{M} \text { and } 24 \mathrm{M} \text {; MMSE score } \\
\text { between } 16 \text { and } 26 \text { inclusive; On stable dose of background ChI and/or } \\
\text { Mem at least } 60 \text { days prior to dosing (not required if the subject had } \\
\text { previously demonstrated a lack of toleration) }\end{array}$ \\
\hline 6M, DB, PC study & 94 & $\begin{array}{l}\text { MMSE score of between } 10 \text { and 24, inclusive } \\
\text { No use of Mem or ChI within } 60 \text { days prior to enrollment }\end{array}$ \\
\hline 26W, DB, PC study & 198 & $\begin{array}{l}\text { MMSE score between } 10 \text { and } 24 \text { inclusive } \\
\text { No use of Mem or ChI within } 90 \text { days prior to enrollment }\end{array}$ \\
\hline $52 \mathrm{~W}, \mathrm{DB}, \mathrm{PC}$ study & 340 & $\begin{array}{l}\text { Visits @ BL, 1W, 2W, 6W, } 13 \mathrm{~W}, 26 \mathrm{~W}, 39 \mathrm{~W} \text {, and } 52 \mathrm{~W} \text {; MMSE score } \\
\text { between } 12 \text { and } 24 \text { inclusive; Taking Dz for at least } 6 \mathrm{M} \text {, with stable } \\
\text { dosing at } 10 \mathrm{mg} \text { /day for at least the last } 4 \mathrm{M} \text { prior to Day } 1\end{array}$ \\
\hline 24W, DB PC study & 104 & $\begin{array}{l}\text { Visits @ BL, } 6 \mathrm{~W}, 12 \mathrm{~W}, 18 \mathrm{~W}, 24 \mathrm{~W} \text {; MMSE scores of } 12 \text { to } 24 \text { inclusive; } \\
\text { No use of Mem or ChI within } 90 \text { days prior to enrollment }\end{array}$ \\
\hline
\end{tabular}

BL, baseline; DB, double blind; Dz, donepezil; ChI, cholinesterase inhibitor; M, month; Mem, memantine; MMSE, Mini-Mental State Examination; PC, placebo controlled; W, week.

\section{References}

1 Caro JJ: Discretely integrated condition event (DICE) simulation for pharmacoeconomics. Pharmacoeconomics 2016;34:665-672.

2 Getsios D, Blume S, Ishak KJ, Maclaine GD: Cost effectiveness of donepezil in the treatment of mild to moderate Alzheimer's disease: a UK evaluation using discrete-event simulation. Pharmacoeconomics 2010;28:411-427.

-3 Getsios D, Blume S, Ishak KJ, Maclaine G, Hernandez L: An economic evaluation of early assessment for Alzheimer's disease in the United Kingdom. Alzheimers Dement 2012;8:22-30.

4 Hartz S, Getsios D, Tao S, Blume S, Maclaine G: Evaluating the cost effectiveness of donepezil in the treatment of Alzheimer's disease in Germany using discrete event simulation. BMC Neurol 2012;12:2.

5 Guo S, Getsios D, Revankar N, Xu P, Thompson G, Bobula J, Lacey L, Gaudig M: Evaluating disease-modifying agents: a simulation framework for Alzheimer's disease. Pharmacoeconomics 2014;32:1129-1139.

6 Bond M, Rogers G, Peters J, Anderson R, Hoyle M, Miners A, Moxham T, Davis S, Thokala P, Wailoo A, Jeffreys $\mathrm{M}$, Hyde C: The effectiveness and cost-effectiveness of donepezil, galantamine, rivastigmine and memantine for the treatment of Alzheimer's disease (review of Technology Appraisal No. 111): a systematic review and economic model. Health Technol Assess 2012;16:1-470.

7 Stern RG, Mohs RC, Davidson M, Schmeidler J, Silverman J, Kramer-Ginsberg E, Searcey T, Bierer L, Davis KL: A longitudinal study of Alzheimer's disease: measurement, rate, and predictors of cognitive deterioration. Am J Psychiatry 1994;151:390-396.

-8 Perneczky R, Wagenpfeil S, Komossa K, Grimmer T, Diehl J, Kurz A: Mapping scores onto stages: mini-mental state examination and clinical dementia rating. Am J Geriatr Psychiatry 2006;14:139-144.

-9 Gustavsson A, Brinck P, Bergvall N, Kolasa K, Wimo A, Winblad B, Jonsson L: Predictors of costs of care in Alzheimer's disease: a multinational sample of 1,222 patients. Alzheimers Dement 2011;7:318-327.

10 Spalletta G, Long JD, Robinson RG, Trequattrini A, Pizzoli S, Caltagirone C, Orfei MD: Longitudinal neuropsychiatric predictors of death in Alzheimer's disease. J Alzheimers Dis 2015;48:627-636.

11 Selbaek G, Kirkevold O, Engedal K: The prevalence of psychiatric symptoms and behavioural disturbances and the use of psychotropic drugs in Norwegian nursing homes. Int J Geriatr Psychiatry 2007;22:843-849.

12 Garre-Olmo J, Lopez-Pousa S, Vilalta-Franch J, de Gracia Blanco M, Vilarrasa AB: Grouping and trajectories of the neuropsychiatric symptoms in patients with Alzheimer's disease. Part I. Symptom clusters. J Alzheimers Dis 2010;22:1157-1167. 